$\checkmark$

Department of Physics

College of Liberal Arts and Sciences

Box 4348, Chicago, Illinois 60680

(312) 996-4868 FAX: (312) 996-9016

17 September 1991

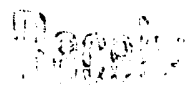

0919901

PROGRESS REPORT

\title{
MOLECULAR DESIGN CONCEPT FOR X-RAY LASER RESEARCH
}

Principal Investigator:

Co-Investigators:

Prepared for:
Charles K. Rhodes

Ting Shan Luk

Armon McPherson

Keith Boyer

Dr. Walter M. Polansky, Director

U.S. DoE

Er-16, GTN

19901 Germantown Rd.

Germantown, MD 20874

\section{DISCLAIMER}

This report was prepared as an account of work sponsored by an agency of the United States Government. Neither the United States Government nor any agency thereof, nor any of their employees, makes any warranty, express or implied, or assumes any legal liability or responsibility for the accuracy, completeness, or usefulness of any information, apparatus, product, or process disclösed, or represents that its use would not infringe privately owned rights. Reference herein to any specific commercial product, process, or service by trade name, trademark, manufacturer, or otherwise does not necessarily constitute or imply its endorsement, recommendation, or favoring by the United States Government or any agency thereof. The views and opinions of authors expressed herein do not necessarily state or reflect those of the United States Government or a yy agency thereof. 


\section{TABLE OF CONTENTS}

ABSTRACT . . . . . . . . . . . . . . . . . . . . . 2

I. INTRODUCTION ........................ 3

II. EXPERIMENTAL APPARATUS ...................... 3

III. DISCUSSION OF EXPERIMENTAL RESULTS . . . . . . . . . . . . . . 4

A. Atomic Ionization . . . . . . . . . . . . . . . . . . . . . . . . 4

B. Molecular Studies . . . . . . . . . . . . . . . . . . . . . . 5

IV. CONCLUSIONS ........................... . . . 6

V. REFERENCES ......................... 11 


\section{ABSTRACT}

The goal of this program is the construction of an x-ray laser in the kilovolt regime. Recent experimental results indicate that a new technique for the generation of strong amplification of $x$-ray wavelengths is feasible. It involves the combination of (1) a new ultrahigh brightness subpicosecond laser technology and (2) a recently discovered unique mode of strong-field interaction, particularly applicable to molecules. A concept of molecular $x$-ray laser design emerges from these considerations which matches the mode of excitation to the structure of the molecular system. The molecular approach enables the combination of very highly electronically excited conditions with an environment characteristic of dense cold matter, a general situation exceptionally conducive to $x$-ray amplification. Both high efficiency and wavelength tunability are intrinsic features of this method. 


\section{INTRODUCTION}

The availability of high peak power ultraviolet (UV) lasers ${ }^{1-7}$ has revolutionized experimental research on the behavior of matter very strong electric fields $(E \geqslant$ $\left.e / a_{0}^{2}\right)$. Moreover, the situation is such that presently available theories are not effective in describing many aspects of the new regime of strong-field coupling being explored. This is particularly true for many-electron systems, a class of materials that includes all molecules. Despite our imperfect understanding of the mechanisms involved in these high-field interactions, recent experimental results suggest that these multiphoton processes can result in a considerable transfer of energy to the irradiated system. For an intensity of $\sim 10^{17} \mathrm{~W} / \mathrm{cm}^{2}$ a total energy transfer exceeding $1 \mathrm{keV}$ has been observed. Consequently, it is expected that total energy transfers considerably above $10 \mathrm{keV}$ will be characteristic of the higher intensities $\left(>10^{19} \mathrm{~W} / \mathrm{cm}^{2}\right.$ ) that will become available in the near future.

Molecules are emerging as a very interesting class of systems for study for at least two reasons. They are the multitude of species available and the experimental finding that the dynamics of the multiphoton coupling is sensitive to the molecular structure of the system. ${ }^{8-10}$ Accordingly, data concerning several molecules, including $\mathrm{N}_{2}, \mathrm{O}_{2}, \mathrm{CO}, \mathrm{N}_{2} \mathrm{O}, \mathrm{CO}_{2}$, and OCS, are under active study.

\section{EXPERIMENTAL APPARATUS}

The laser system used in these experiments is shown schematically in Fig. (1). Since it has been described in detail elsewhere, its description here will be brief. It has three main components; they are an amplified infrared seed laser, wavelength conversion crystals, and UV excimer amplifiers. A recent modification to the system incorporates a $\mathrm{Ti}_{2} \mathrm{Al}_{2} \mathrm{O}_{3}$ amplifier for amplification of the $745 \mathrm{~nm}$ radiation before conversion to the UV. This has resulted in a 40-fold increase (to $\sim 40 \mu \mathrm{J}$ ) in the $248 \mathrm{~nm}$ output energy from the crystals, greatly enhancing the overall 
performance of the entire system. Railgaps have also been added to the power amplifier to improve its performance.

The system has a final output pulse width of $\sim 600$ is and a pulse energy of $\sim 500 \mathrm{~mJ}$. Stringent measures have been taken throughout the entire laser system to ensure high spatial quality of the output. This has resulted in a focusability which is within a factor of two of the diffraction limit for a $10 \mathrm{~cm}$ diameter beam. Indeed, with the use of a simple $F / 10$ lens, peak intensities approaching a value of $\sim 10^{17}$ can be produced, even in the presence of significant spherical aberration. Higher intensities are now available with the use of an F/6 mirror.

\section{DISCUSSION OF EXPERIMENTAL RESULTS}

\section{A. Atomic Ionization}

The measurement of the ionization of free atoms can be used to give an estimate of the peak field strength produced in the focal zone where the ionized atoms are produceu. This can be done with the use of models involving tunneling ionization. ${ }^{11-17}$

Measurements of $\mathrm{Kr}$ have been performed in order to appraise the maximum intensity produced. The result, as presented in the ion time-of-flight spectrum, are illustrated in Fig. (2). Clearly seen are signals from $\mathrm{Kr}^{8 *}$ and $\mathrm{Kr}^{9 *}$ and a weak, but discernable, presence of $\mathrm{Kr}^{12+}$ is also visible. The $\mathrm{O}^{2+}$ peak arising from an impurity of $\mathrm{H}_{2} \mathrm{O}$ in the chamber, masks the $\mathrm{Kr}^{20+}$ signal that occurs in its vicinity. Note the prominent isotopic splittings that are associated with the $\mathrm{Kr}^{8+}$ signal.

The representation given in Fig. (3) combines experimental data on the threshold intensities for ion production in $\mathrm{Kr}$ with the corresponding predictions of several theoretical models. The measured datum for $\mathrm{Kr}^{11+}(Z=11)$, which has $^{18} E_{p} \simeq 318 \mathrm{eV}$ and is explicitly shown, gives $I_{\text {th }} \simeq 2 \times 10^{17} \mathrm{~W} / \mathrm{cm}^{2}$. This 
experimental value is within approximately a factor of two of that predicted by the 1-D picture. ${ }^{11}$ This would give a peak field of $\sim 2.4\left(\mathrm{e} / \mathrm{a}_{0}^{2}\right)=1.2 \times 10^{20}$ $\mathrm{V} / \mathrm{cm}$ produced by the ultraviolet wave.

\section{B. Molecular Studies}

A series of experiments has been begun on molecular systems. Data havu been taken for $\mathrm{N}_{2}, \mathrm{O}_{2}, \mathrm{CO}, \mathrm{N}_{2} \mathrm{O}$, and $\mathrm{CO}_{2}$ and we are currently in the process of evaluating this information. In order to present certain features of these new data, we now explore some of the results for $\mathrm{CO}_{2}$.

In previous preliminary work, ${ }^{19}$ certain aspects of the problem of fragmentation exhibited by $\mathrm{CO}_{2}$ have been discussed. These earlier data ${ }^{19}$ were taken with a peak intensity of $\sim 3 \times 10^{16} \mathrm{~W} / \mathrm{cm}^{2}$ and the observed kinetic energy distribution for the $\mathrm{O}^{3+}$ channel is shown in Fig. (4A). In this case, most of the observed ions had kinetic energies below $\sim 65 \mathrm{eV}$.

The intensity dependence ${ }^{9}$ of the distributions of kinetic energy can reveal important properties of the molecular coupling. The production of $\mathrm{Kr}^{12 *}$, as discussed in paragraph III.A above, demonstrates that the improved focusing system currently being used produces a maximum intensity $I_{m} \sim 2 \times 10^{17} \mathrm{~W} / \mathrm{cm}^{2}$, a value considerably higher than available in the earlier work. ${ }^{19}$ Figure (4B) illustrates the kinetic energy spectrum for the $\mathrm{O}^{3 *}$ channel observed from $\mathrm{CO}_{2}$ with this higher value for the maximum intensity. Under these conditions, the peak in the kinetic energy distribution occurs at $\sim 65 \mathrm{eV}$ and a discernable signal exists even in the $90-100 \mathrm{eV}$ range. A comparison of these data with the results appearing in Fig. (4A) clearly illustrates a significant shift of the distribution to higher kinetic energies. The mean energy of the $\mathrm{O}^{3+}$ ions is roughly doubled in going from $\sim 3 \times 10^{16} \mathrm{~W} / \mathrm{cm}^{2}$ to $\sim 2 \times 10^{17} \mathrm{~W} / \mathrm{cm}^{2}$ in the maximum intensity. 
This result indicates that considerably more energy has been transferred to the molecule prior to fragmentation by the stronger external field.

\section{CONCLUSIONS}

A program of molecular studies has commenced for the evaluation of a new concept for $x$-ray amplification. Data on several systems, including $\mathrm{N}_{2}, \mathrm{O}_{2}, \mathrm{CO}$, $\mathrm{N}_{2} \mathrm{O}$, and $\mathrm{CO}_{2}$, have been obtained and are currently being analyzed. We plan to continue this line of inquiry and extend it to other molecular systems such as $S F_{6}$ and $U F_{8}$. 


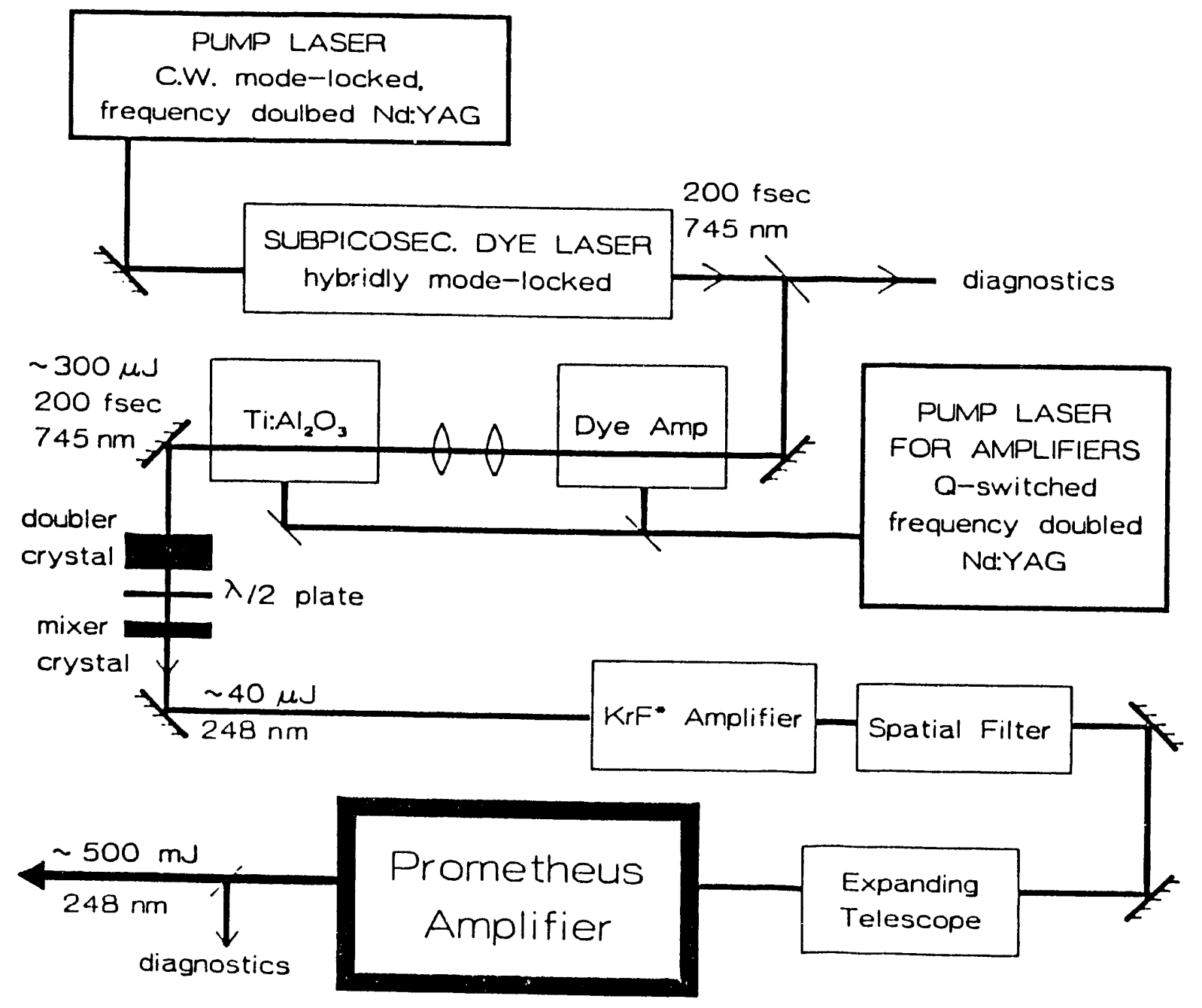

Fig. (1): A schematic of the high intensity KrF laser system. 

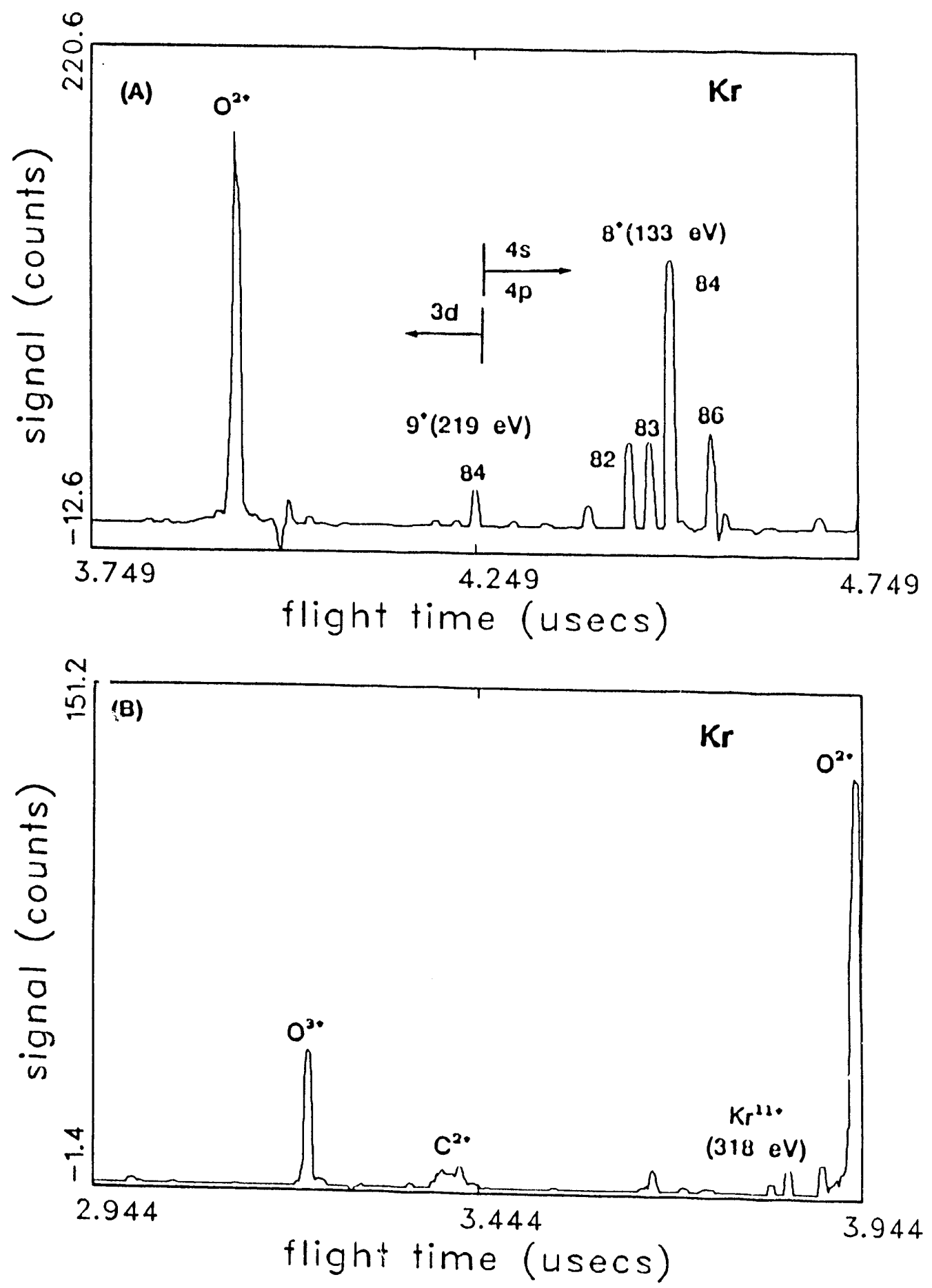

Fig. (2): Time-of-flight ion spectrum of $\mathrm{Kr}$. (A) The region showing $\mathrm{Kr}^{\mathrm{B} *}$ and $\mathrm{Ki}^{-9 *}$ with appropriate isotopic mass numbers identifying the peaks. Ionization with $\mathrm{q} \geqslant 9$ must involve the $3 d$ shell. The $\mathrm{Kr}^{20 *}$ signal is obscured by the $\mathrm{O}^{2 *}$ signal arising from $\mathrm{H}_{2} \mathrm{O}$ present as an impurity. (B) The region showing $\mathrm{Kr}^{21 *}$. $\mathrm{O}^{2+}, \mathrm{O}^{3 *}$, and $\mathrm{C}^{2 *}$ signals stemming from impurities are also identified. The ionization energies associated with the production of $\mathrm{Kr}^{8 *}, \mathrm{Kr}^{9 *}$, and $\mathrm{Kr}^{11 *}$ sptcies are shown as $133 \mathrm{eV}, \sim 219 \mathrm{eV}$, and $\sim 318 \mathrm{eV}$, respectively, in these panels. 


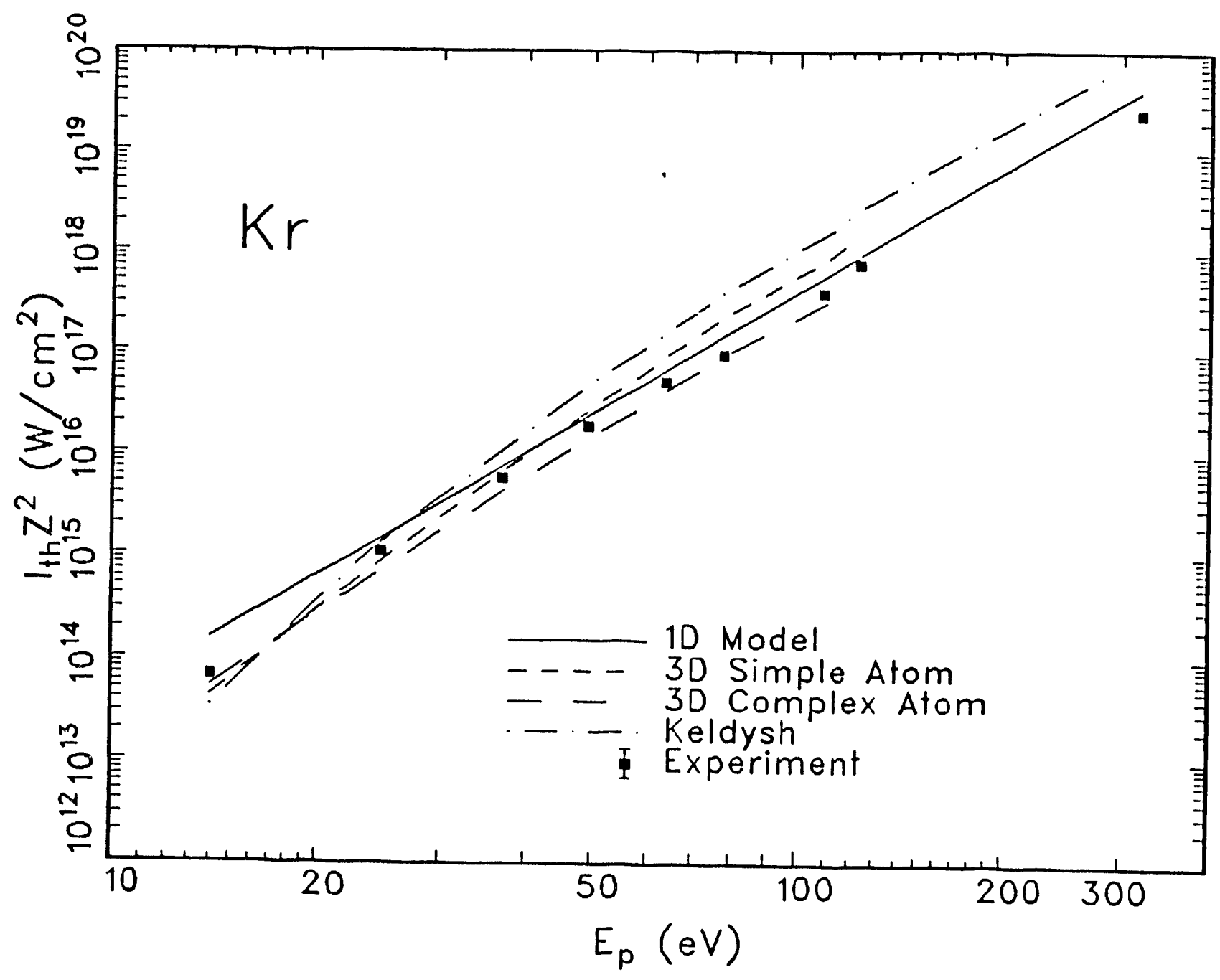

Fig. (3): Scaled threshold ionization intensities $I_{\text {th }}$ as a function of ionization potential $E_{p}$ for $\mathrm{Kr}$ along with calculated results from various theories. The parameter $Z$ represents the final ionic charge. The theoretical curves corresponds to a 1-D model, 3-D simple atom picture, a 3-D complex atom model and the Keldysh theory, as discussed in Ref. (17). Experimental data are also shown, in particular for the point corresponding to $\mathrm{Kr}^{11}$. $\left(E_{p}=318 \mathrm{eV}\right)$. 

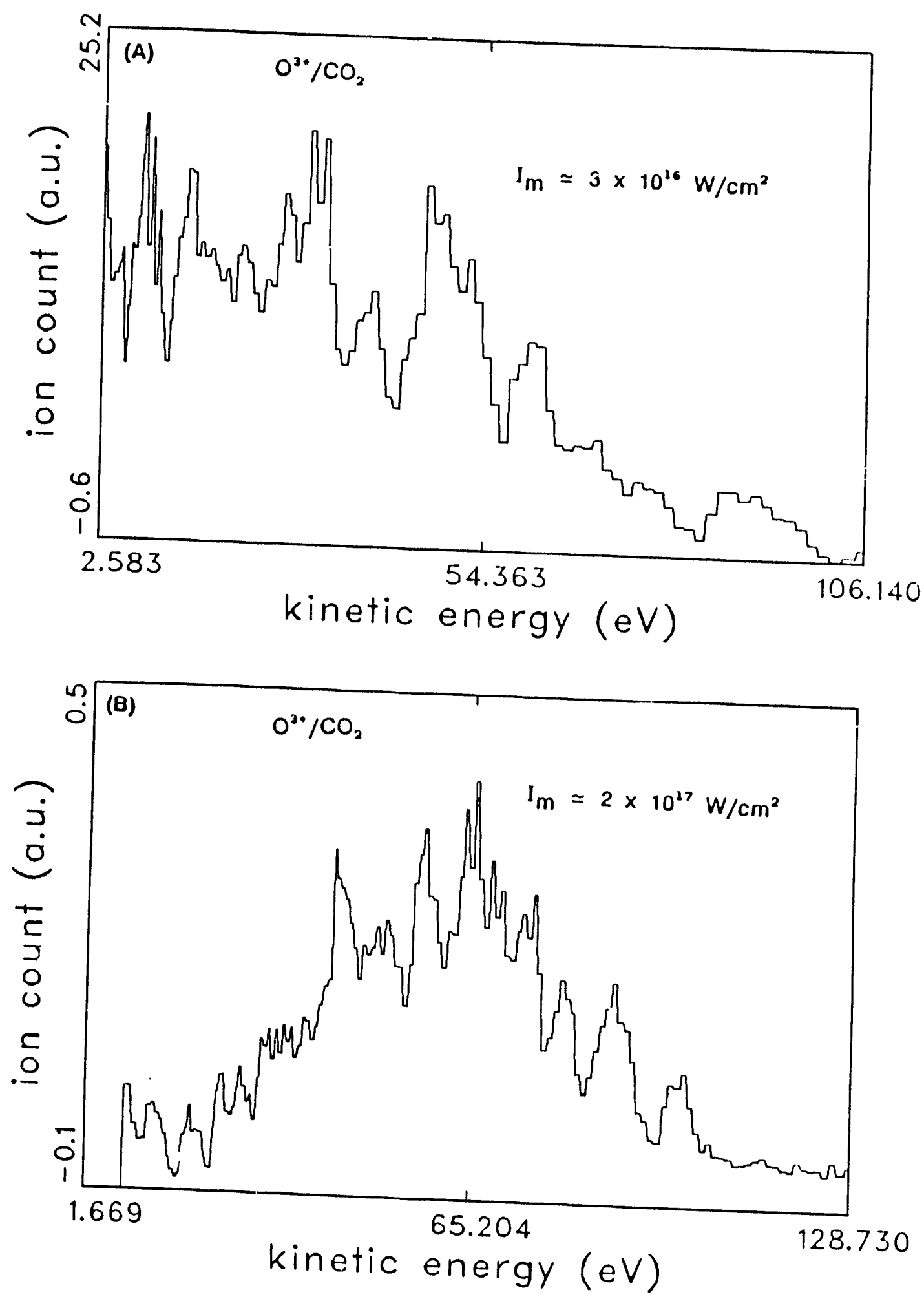

Fig. (4): Kinetic energy spectra for $\mathrm{O}^{3 *}$ from $\mathrm{CO}_{2}$. $(\mathrm{A})$ Ion distribution obtained with a maximum UV intensity $I_{\mathrm{m}} \sim 3 \times 10^{16} \mathrm{~W} / \mathrm{cm}^{2}$. Most ions have an intensity $I_{m} \simeq 2 \times 10^{17} \mathrm{~W} / \mathrm{cm}^{2}$ distribution observed with a maximum UV occurs at $\sim 65 \mathrm{eV}$. 


\section{REFERENCES}

1. S. Szatmári, F. P. Schäfer, E. Müller-Horsche, and W. Mückenheim, "Hybrid Dye-Excimer Laser System for the Generation of $80 \mathrm{fs}, 900 \mathrm{GW}$ Pulses at 248 nm." Opt. Comm. 63, 305 (1987).

2. A. Endoh, M. Watanabe, N. Sarukura, and S. Watanabe, "Multiterawatt Subpicosecond KrF Laser," Opt. Lett. Z, 353 (1989).

3. J. R. M. Barr, N. J. Everall, C. J. Hooker, I. N. Ross, M. J. Shaw, W. T. Toner, "High Energy Amplification of Picosecond Pulses at 248 nm," Opt. Comm. 66, 127 (1988).

4. J. G. Glownia, J. Misevich, and P. P. Sorokin, "160-fsec XeCl Excimer Amplifier System," J. Opt. Soc. Am. B4, 1061 (1987).

5. A. P. Schwarzenbach, T. S. Luk, I. A. Mciniyizo, U. Johann, A. McPherson, K. Boyer, and C. K. Rhodes, "Subplcosecond KrF" Excimer-Laser Source," Opt. Lett. 11. 499 (1986).

6. J. P. Roberts, A. I. Taylor, P. H. Y. Lee, and R. B. Gibson, "High-Irradiance 248-nm Laser System," Opt. Lett. 13, 734 (1988).

7. T. S. Luk, A. McPherson, G. Gibson, K. Boyer, and C. K. Rhodes, "UltrahighIntensity KrF* Laser System," Opt. Lett. 14. 1113 (1989).

8. L. J. Frasinski, K. Codling, and P. A. Hatherly, "Covariance Mapping: A Correlation Method Applied to Multiphoton Multiple Ionization," Science 246, 1029 (1989).

9. L. Lavancier, D. Normand, C. Cornaggia, J. Morellec, and H. X. Lin, "LaserIntensity Rependence of the Multielectron Ionization of $C O$ at 305 and 610 nm, Phys. Rev. A 43, 1461 (1991).

10. T. S. Luk, A. McPherson, G. N. Gibson, K. Boyer, and C. K. Rhodes, "Molecules X-Ray Laser Research," Izvestla Academia Nauk. Seria Fizicheskaya, T. 55, 768 (1991) (in Russian): English Translation to be published in the Proceedings of the International Symposium, "Short Wavelength Lasers and Applications," Samarcand, USSR, 14-18 May 1990.

11. S. Augst, Strlckland, D. D. Meyerhofer, S. L. Chin, and J. H. Eberly, "Tunneling Ionization of Noble Gases in a High-Intensity Laser Field," Phys. Rev. Lett. 63, 2212 (1989).

12. N. H. Burnett and P. B. Corkum, "Cold-Plasma Production for Recombination Extreme-Ultraviolet Lasers by Optical-Field-Induced Ionization," J. Opt. Soc. Am. B 6, 1195 (1989).

13. D. Landau and E. M. Lifshitz, Quantum Mechanics, 3rd ed. (Pergamon, London,

14. B. M. Smirnov and M. I. Chibisov, "The Breaking up of Atomic Particles by an Electric Field and by Electron Collisions," Zh. Eksp. Teor. Fiz. 49, 841 (1965) [Sov. Phys. - JETP 22, 585 (1966).

15. A. M. Perelomov, V. S. Popov, and $M$. V. Terent'ev, "Ionization of Atoms in an Alternating Electric Field," Zh. Eksp. Teor. Fiz. 50, 1393 (1966) [Sov. Phys.
- JETP 23, 924 (1986)].

16. M. V. Ammiosov, N. B. Delone, and V. P. Krainov, "Tunnel Ionization of Complex Atoms and of Atomic Ions in an Alternating Electromagnetic Field," Zh. Eksp. Teor. Fiz. 64, 2008 (1986) [Sov. Phys. - JETP 64, 1191 (1991)].

17. G. N. Gibson, T. S. Luk, and C. K. Rhodes, "Tunneling Ionization in the Multiphoton Regime," Phys. Rev. A 41, 5049 (1990).

18. Thomas A. Carlson, C. W. Nestor, Jr., Niel Wasserman, and J. D. McDowell, "Calculated Ionization Potentials for Multiply Charged Ions," Atomic Data $\underline{2}^{\text {, }}$

19. T. S. Luk, A. McPherson, B. E. Bouma, K. Boyer, and C. K. Rhodes, "Studies of the Interaction of Molecules and Solids with Intense Subpicosecond 248 nm Radiation," in Multiphoton Processes, edited by G. Mainfray and P. Agostini (CEA, Saclay, 1991) p. 217. 

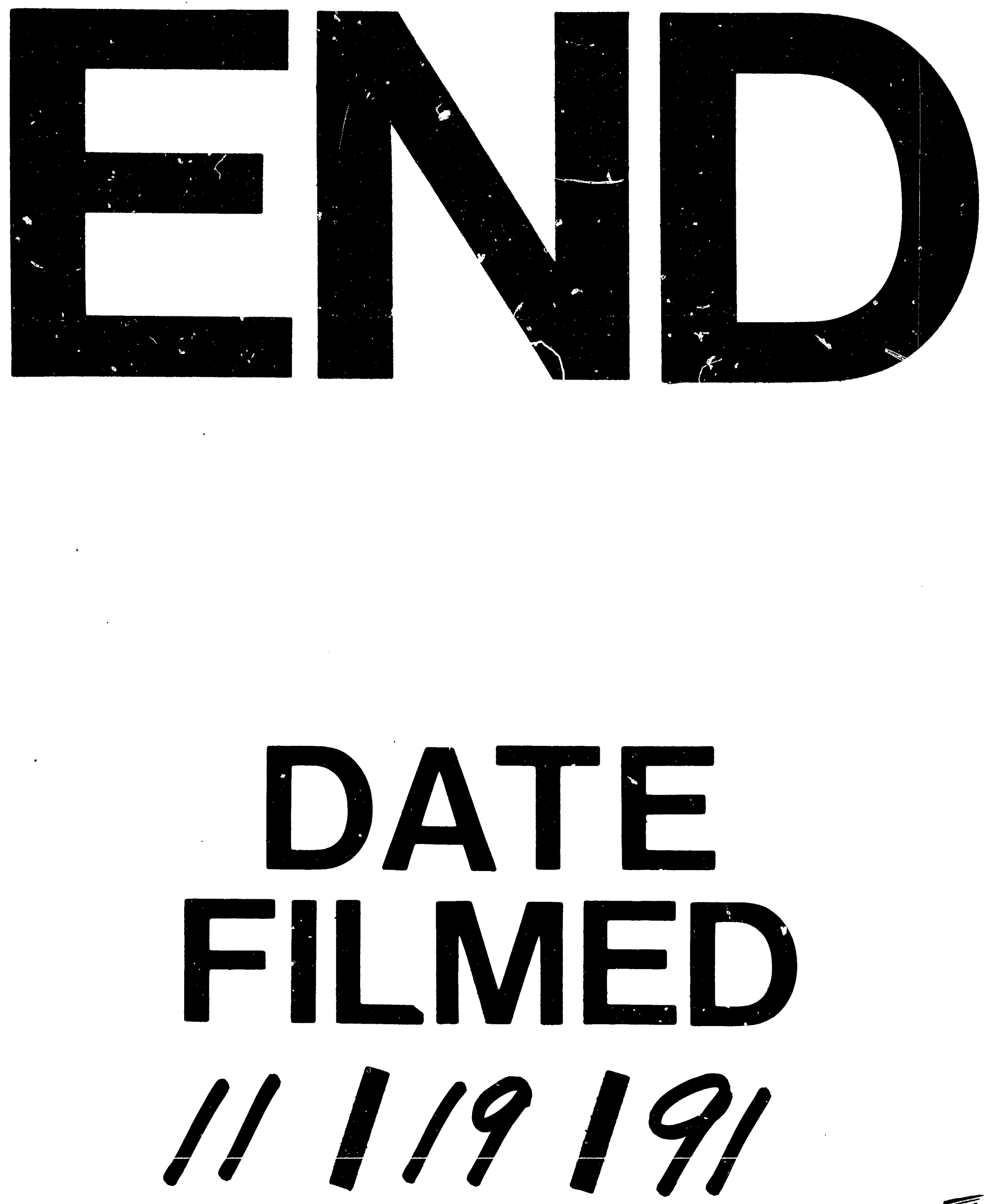

I 
